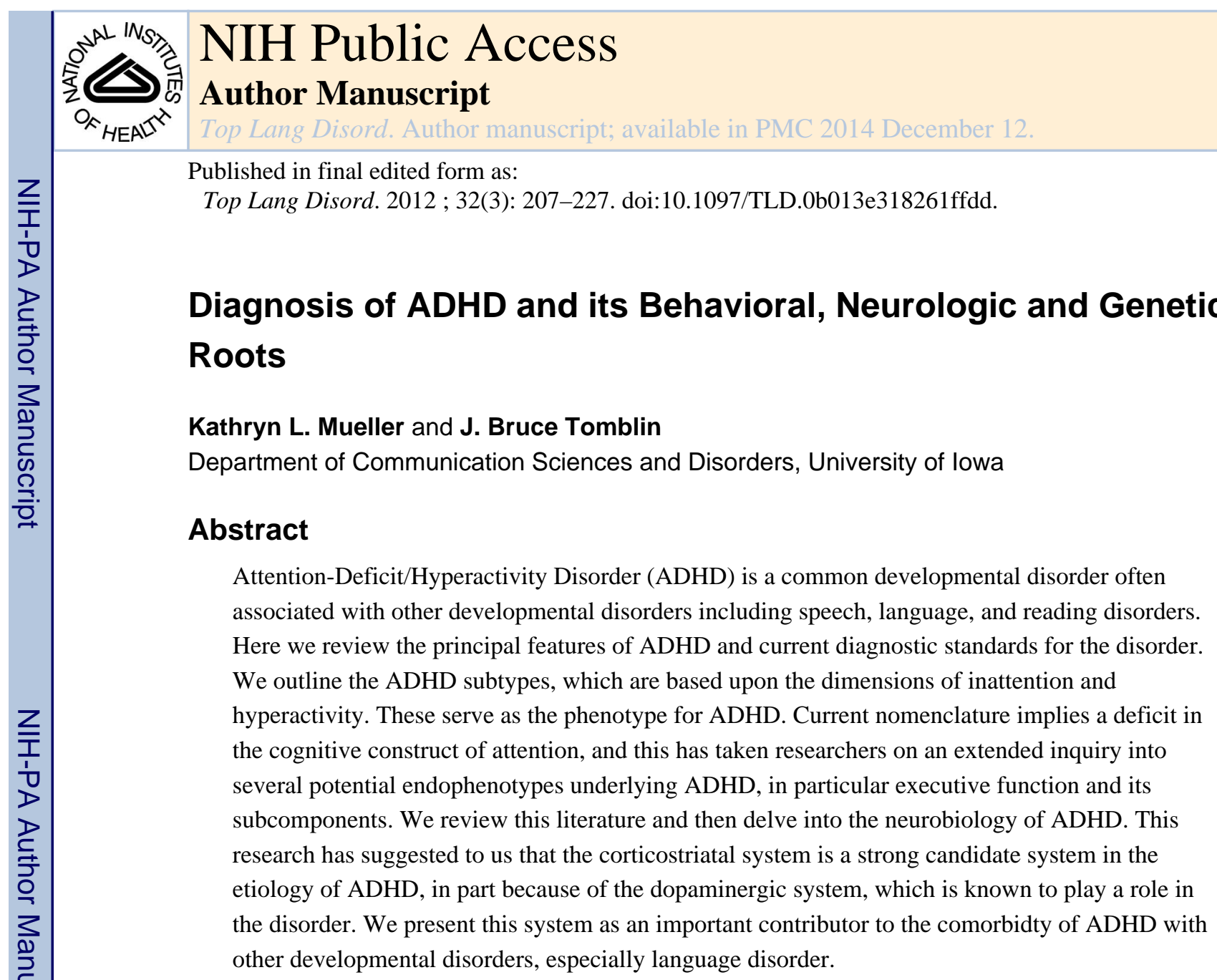

Keywords

ADHD; basal ganglia; dopamine; etiology genetics

This issue of Topics in Language Disorders is based on the premise that the study of comorbidity can aid us in better understanding the nature and, in particular, the causes of developmental disorders. In the companion paper preceding this (Tomblin and Mueller, 2012), we introduced the idea that comorbidity can arise for a variety of reasons. Some of these are to do with overlaps at the symptom, or phenotype level; whereas others are the result of overlaps in the causal pathways leading to these disorders. Tomblin and Mueller (2012) presented a hypothetical model of comorbidity, exemplifying the etiologic pathways and symptom overlap that may exist between communication disorders and ADHD. The model depicted a symptom (phenotype) level and intermediate endophenotypes, with input from genes and the environment. In this paper, we provide an overview of ADHD across the levels of phenotype, endophenotype, and genetics with the aim of considering the possible sources of overlap between ADHD and speech, language, and reading disorders.

Corresponding Author: Kathryn Mueller, Department of Communication Sciences and Disorders, University of Iowa, Iowa City, IA 52242, kathryn-mueller@uiowa.edu.

J. Bruce Tomblin, Professor, Communication Sciences and Disorders; Kathryn L. Mueller, Doctoral Candidate, Communication

Sciences and Disorders 


\section{INTRODUCTION TO ADHD}

ADHD is a common neurodevelopmental disorder that affects $8-12 \%$ of children worldwide (for a review see: Faraone, Sergeant, Gillberg, \& Biederman, 2003; Pastor \& Reuben, 2008). This rate drops to $4 \%$ in adulthood (Kessler et al., 2005), arguably as a reflection of the way in which the disorder is defined, as opposed to the fact that individuals show real 'recovery' over time (Barkley, Murphy, \& Fischer, 2010; Faraone, Biederman, \& Mick, 2006). Indeed, the effects of ADHD are both chronic and pervasive. Individuals with the disorder attain lower educational and occupational levels and experience higher rates of unemployment than would otherwise be expected given their cognitive abilities (Curt \& Stabile, 2004; Farone, Biederman, \& Kiely, 1996; Kessler et al., 2005). Social and familial relationships are affected (Harpin, 2005). Additionally, it has been well documented that individuals with ADHD are at increased risk for additional psychopathology later in adulthood (Frick \& Nigg, 2012; E. G. Willcutt, Hartung, Lahey, Loney, \& Pelham, 1999).

There is no single clinical or molecular marker for ADHD. In spite of this, ADHD is one of the best-validated clinical diagnoses of childhood psychiatric disorders (Farone et al., 2000). Diagnosis is based on the observation of certain behavioral symptoms in everyday activities. As we will see later, there are ongoing efforts to develop more standardized psychometric measures for the disorder, but so far these are supplementary to behavioral information.

Diagnostic standards for ADHD are laid out in the Diagnostic and Statistical Manual of Mental Disorders (American Psychiatric, 2000), which characterizes the disorder as persistent, cross-situational levels of inattentive, impulsive, and hyperactive behaviors that are both developmentally inappropriate and impairing. These standards are also endorsed by the American Academy of Pediatrics, in their 2000 guidelines (Disorder, 2000). Under this taxonomy, two symptom clusters of inattention and hyperactivity/impulsivity are recognized, giving rise to three subtypes of ADHD: i) ADHD, Predominantly Inattentive (ADHD-IA); ii) ADHD, Predominantly Hyperactive-Impulsive (ADHD-H/I); and iii) ADHD, Combined type (ADHD-C). Children are diagnosed as clinical on the basis of six or more symptoms of either inattention, hyperactivity, or both (ADHD-C), as laid out in the $D S M$-IV-TR checklist (Table 1). Symptoms must emerge before age seven and have caused impairment for at least 6 months.

Clinical interview is one of the most effective ways to identify ADHD (Davidson, 2008). $D S M-I V-T R$ guidelines stipulate behavioral symptoms should be present across two or more settings (e.g. home and school), so parents and teachers are often asked to complete behavioral rating scales like The Child Behavior Checklist (CBCL) and The Teacher Report Form (TRF; (Achenbach \& Rescorla, 2001); The Conners Comprehensive Behavior Rating Scales (Conners, 2008); or the ADHD Rating Scale-IV (DuPaul, Power, Anastopoulos, \& Reid, 1998) as part of a differential diagnosis (for instance see: Davidson, 2008). These provide quantitative information on a range of behaviors, along with diagnostic information. Although many of these scales parallel the diagnostic system laid out in the DSM-IV, they are not always entirely the same. Most of the scales are norm-referenced. Various cut-offs have been proposed for the point at which a child should be diagnosed as clinical according to these scales, ranging between -1 and -2 SD (Achenbach \& Rescorla 2001; DuPaul, 
1998). Barkley (2005), one of the most prominent researchers in ADHD, has recommended a cut-off of -1.5 .

\section{EPIDEMIOLOGY OF ADHD}

A number of studies have published data on the prevalence of ADHD. Not surprisingly, these are influenced by many factors, including the manner in which the diagnosis is made, the age of the individuals sampled, and the study design. The APA estimates the prevalence of ADHD to be between $3 \%$ and $7 \%$. Some research studies estimate it as higher, in the range of $8 \%$ to12\% (Alloway, Elliott, \& Holmes, 2010; Faraone et al., 2003). Historically, ADHD has been conceptualized as a childhood disorder, and current DSM-IV-TR guidelines reflect this. However, there is considerable controversy surrounding the age of onset requirement on the basis of both empirical (Applegate et al., 1997; Barkley \& Biederman, 1997) and theoretical grounds (Faraone et al., 2006; Li et al., 2006; McGough \& Barkley, 2004). The same DSM-IV-TR criteria are used in the diagnosis of adults even though they have never been validated (McGough \& Barkley, 2004), and many are obviously not applicable to older individuals (e.g., runs and climbs excessively). Although the prevalence ADHD does decline with age (Kessler et al., 2005), there is now strong evidence, including data from longitudinal studies, that symptoms persist through adolescence (Barkley, Fischer, Smallish, \& Fletcher, 2002; Faraone, Biederman, \& Monuteaux, 2002) and into adulthood (Davidson, 2008). One study showed that approximately $4 \%$ of adults in the US experience symptoms of ADHD that warrant a clinical diagnosis (Kessler et al., 2005). It has been suggested that symptoms of ADHD in adulthood manifest in legal problems (Heiligenstein \& Keeling, 1995), challenges in the workplace (Kessler et al., 2005), and driving difficulties (Murphy \& Barkley, 1996); and these have been proposed as specific adult criteria for ADHD in the next edition of the DSM (Ramsay \& Rostain, 2006).

Studies on gender differences in ADHD indicate that more boys are diagnosed with the disorder than girls, with male to female ratios ranging from 3:1 to 9:1 (Lahey et al., 1994; Scahill \& Schwab-Stone, 2009; Szatmari, Offord, \& Boyle, 1989). The male-to-female sex ratio is greater in clinical than community studies, indicating that females are less likely to be referred for services than males (Biederman \& Faraone, 2005). These differences have been argued to be the result of the how the ADHD profile manifests in males versus females. The DSM-IV field trials indicated that ADHD subtypes differ significantly on variables such as age of onset, gender ratio, and level of social and academic impairment (Lahey et al., 1994), and several studies have shown that ADHD is less disruptive in women than in men (Biederman \& Faraone, 2004). Both Gaub and Carlson (1997) and Gershon (2002) have reported that although females exhibit higher rates of ADHD-IA than males, they exhibit lower rates of ADHD-H/I and fewer overall symptoms, which probably leads to underidentification of the disorder in this group.

\section{DIMENSIONALITY OF THE DSM-IV-TR SUBTYPES}

Children with ADHD represent a highly heterogeneous group. The current taxonomy was derived empirically from factor analyses of symptom lists, performed as part of the DSM-IV field trials (Lahey et al., 1994; Neuman et al., 1999). Factor analysis supports the notion that

Top Lang Disord. Author manuscript; available in PMC 2014 December 12. 
there are two psychometrically defensible latent traits underlying ADHD (i.e. inattention and hyperactivity), which unify and explain the symptom clusters and their associated behaviors. Although the two symptom dimensions of inattention and hyperactivity are highly correlated, research on ADHD subtypes has demonstrated they differ in profile and impairment (for a review, see Willcutt et al., 2001 and Willcutt et al., in press). The dimension of inattention is associated with general deficits in processing and vigilance. Children with the ADHD-IA subtype tend to have more problems with focused/selective attention, daydreaming, and sluggish information processing (McBurnett et al., 1999). A study of the external correlates of ADHD has shown that children in this group are more likely to meet criteria for learning disability than those in the ADHD-H/I group (Davidson, 2008; E. Willcutt \& Pennington, 2000). Furthermore, if the effects of the hyperactivity are controlled for statistically, symptoms of inattention are significantly related to academic underachievement, whereas symptoms of hyperactivity and impulsivity are not. Lahey et al. (1994) have also shown that inattentive, and not hyperactive-impulsive behaviors are significantly related to parent and teacher ratings of school difficulties. In comparison, children with ADHD-H/I have more problems with the persistence of effort, and distractibility. Barkley (1997) has proposed the dimension of hyperactivity is associated with deficits in behavioral inhibition. Because it shares elements with both inattention and hyperactivity, children with ADHD-C subtype are likely to exhibit deficits across a range of domains. Further evidence for this will be reviewed in the section on cognitive functions in ADHD.

There has been some debate as to whether ADHD subtypes remain stable over time (see Willcutt et al., in press, for a review). To examine this, Lahey et al. (2005) followed children with ADHD (all subtypes) for eight years (Lahey, Pelham, Loney, Lee, \& Willcutt, 2005). They found that although the diagnosis of ADHD was relatively stable, children frequently moved between subtypes. This finding was common to all subtypes, although children initially diagnosed with either ADHD-IA or ADHD-H/I were more likely to be diagnosed with a different subtype in the future. In explaining this, Lahey et al. (2005) conceptualized ADHD-H/I as a less severe form of ADHD-C, which either naturally remits or becomes more severe with age, resulting in ADHD-C. Barkley (1997) has also proposed ADHD-H/I as an antecedent condition to ADHD-C. Some researchers have even proposed that ADHDIA should be considered a distinct disorder in the next edition of the DSM (Lahey et al., 2005; Milich, Balentine, \& Lynam, 2001). Studies of neuropsychological function in the subtypes of ADHD have produced mixed results (Chhabildas, Pennington, \& Willcutt, 2001).

\section{COGNITIVE ENDOPHENOTYPES OF ADHD}

A considerable amount of research on ADHD has been devoted to characterizing specific cognitive deficits in the disorder, with the aim of finding fundamental causal mechanisms and endophenotypic markers. Our current understanding is derived almost exclusively from neuropsychological testing, which has revealed a number of well-replicated differences between children with and without ADHD. In the section that follows, we review the evidence for these as endophenotypes for the disorder. 
To examine the magnitude of cognitive differences between individuals with and without ADHD, Frazier, Demaree and Youngstrom (2004) performed a meta-analysis of several neuropsychological and cognitive assessments commonly used in the identification of the disorder. Many of these are described below. They found effect sizes for overall cognitive ability (reported as values of Cohen's $d$, reflecting differences in group means in standard deviation units) were significantly different between the two groups. In comparison, measures of specific cognitive ability were not, suggesting that individually, neuropsychological tests may not be that informative in the study of ADHD. Nigg (2005) has also noted modest effect sizes for specific cognitive measures in ADHD, "raising serious question as to the ability of any one neuropsychologic hypothesis to fully account for [the disorder]" (p. 1432).

This failure to find robust cognitive markers for ADHD is not unusual in the study developmental disorders, and probably reflects the complexity and relatedness of the developmental processes involved (Karmiloff-Smith, 1998). Nevertheless, most research in ADHD continues to search for a coherent cognitive profile that will explain the disorder. Nigg (2005) reviewed 626 papers on the neuropsychology of ADHD published between 1990 and 2004. He concluded the majority of research could be organized according to four broad areas: (1) attention, (2) executive functions, (3) state regulation, and (4) processing of temporal information. These will be reviewed below.

\section{Attention}

The clinical label in general, and the ADHD-IA subtype in particular, suggests ADHD is a disorder of attention. As in many disciplines, understanding of this construct is confounded by an abundance of concepts, definitions, methods, and theories, a review of which is certainly beyond the scope of this article. Nigg (2005) narrowed attention to mean stimulusdriven orienting and selection. The critical point here is that attention is the result of both bottom-up and top-down processing. Bottom up processing is stimulus-driven and relatively automatic, whereas top-down processing is goal-driven, effortful, and controlled.

Developmental research suggests that children's attentional resource capacity and their ability to allocate these resources effectively improves throughout adolescence (e.g., Gathercole, 1999), and deficits in this area would be consistent with items on ADHD asking whether the child acts young.

Parents and teachers frequently perceive children with ADHD as being easily distracted by extraneous stimuli in the environment. Evidence for this, however, is rather weak (Steinkamp, 1980; Rosa van Mourik, Oosterlaan, Heslenfeld, Konig, \& Sergeant, 2007). Nigg (2005) concluded that neither top-down nor bottom-up processing in attention was impaired in ADHD. Consequently, it has been argued that inattentive symptoms in ADHD are not so much the product of distractibility, as a reflection of deficits in persistent and sustained attention, which is collectively termed 'vigilance'. Barkley (2005) has noted vigilance to be grounded in difficulties with "cognitive loading or difficulty with the task (working memory) and its demands for the protection of executive actions (thinking) through interference control" (p.78). As we will see in the next section, research in ADHD

Top Lang Disord. Author manuscript; available in PMC 2014 December 12. 
has focused heavily on the theory of executive function (EF) as the primary causal deficit for the disorder (Barkley, 1997; B. F. Pennington \& Ozonoff, 1996).

\section{Executive Function}

The EF hypothesis of ADHD stems from observations that prefrontal lesions sometimes produce behavioral symptoms of hyperactivity or impulsivity that are characteristic of the disorder, as well as deficits on EF tasks (E. G. Willcutt, Doyle, Nigg, Faraone, \& Pennington, 2005). The pathophysiology of ADHD likely involves dysfunction of the dopaminergic and noradrenergic pathways in the prefrontal cortex and subcortical regions of the brain that support EF (Barkley, Grodzinsky, \& DuPaul, 1992; Konrad, Neufang, Hanisch, Fink, \& Herpertz-Dahlmann, 2005). Several lines of evidence implicate aberrant dopaminergic neurotransmission as one underlying pathological mechanism of ADHD. Individuals with ADHD have abnormal levels of the dopamine transporter (SLC6A3/DAT1) in brain regions that are rich in dopamine activity, including the striatum, mid-brain, and frontal cortex (e.g. Castellanos et al., 1996; Faraone \& Biederman, 1998; Spencer et al., 2005). Psychostimulant drugs ${ }^{1}$, commonly used in the treatment of ADHD, occlude dopamine receptors, thereby blocking dopamine reuptake from the synaptic cleft, and increasing the availability of dopamine at the synapse (e.g. Roman et al., 2002).

Pharmacological studies indicate that, as well as alleviating ADHD symptoms, these drugs also help improve performance on EF tasks (Schachar, Tannock, Cunningham, \& Corkum, 1997).

Executive function is an umbrella term used to refer to "neurocognitive processes that maintain an appropriate problem-solving set to attain a later goal" (E. G. Willcutt et al., 2005). Willcutt and colleagues (2005) conducted a meta-analysis of the literature on EFs in ADHD. They identified 13 neuropsychological measures frequently administered (see:

Table 3) and used factor analysis to show these could be subdivided into four sub-domains: (1) response inhibition, (2) working memory (verbal and nonverbal), (3) set-shifting and task switching, and (4) interference control. Other researchers have proposed similar frameworks. For example, Barkley (1997) has suggested EFs can be split into measures of: (1) nonverbal working memory, (2) verbal working memory, (3) self-regulation, and (4) reconstitution. Willcutt et al.'s (2005) scheme has the advantage of being empirically based, so we will follow this taxonomy.

Response Inhibition and Execution-This construct arises from the observation that individuals with ADHD frequently act impulsively, seemingly without thinking, or at least without carefully considered control strategies (Barkley, 1997; B. F. Pennington \& Ozonoff, 1996). Inhibition comes into play in situations that require the sudden interruption of an ongoing thought or action, or the suppression of information that one wishes to ignore. It is frequently measured using the Stop-Signal task. This is a straightforward dual-task computer paradigm: the participant sees a letter appear on the computer screen and responds by pressing the appropriate button on the keyboard (e.g. X or O). When the visual cue is accompanied by an auditory tone, the participant must inhibit this response (i.e. not press the

\footnotetext{
${ }^{1}$ For example, methypehnidate (Ritalin) and mixed amphetamine (Adderall).
} 
key). Another commonly used measure of inhibition is the continuous performance task (CPT). An example of this is the A-X task. It is similar to the Stop-Signal task: letters appear on the computer screen and the participant must respond by pressing a button, except in cases when the letter $\mathrm{X}$ is preceded by the letter $\mathrm{A}$. Two types of errors are measured on this task: commission errors and omission errors. Commission errors are responses to a sequence other than the target sequence. These reflect problems with inhibition. Omission errors are instances in which the subject fails to respond to the target sequence. These reflect deficits in vigilance.

Several studies have shown that children with ADHD exhibit slower Stop-Signal reaction times than normal controls (for a review see Oosterlaan, Logan, \& Sergeant, 1998). In Willcutt et al.'s (2005) meta-analysis there were 27 studies using the Stop-Signal task, collectively resulting in a modest effect size: Cohen's $d=0.61,95 \%$ CI $[.52, .70]$. Of these studies, $82 \%$ found a significant difference in performance between groups with ADHD and controls $(p<.05)$. Results such as these have been used to suggest that hyperactive and impulsive behaviors in ADHD arise as a result of slowed "stop" processes, as opposed to fast "go" processes. There were a similar number of studies examining CPT in this analysis. The average effect size for commission errors was $d=0.51,95 \%$ CI $[.43, .59]$; the average effect size for omission errors was $d=0.64,95 \%$ CI $[.55, .73]$. Given that response inhibition is considered to be a core deficit in ADHD, it is perhaps surprising to see only medium effect sizes in these studies. The theory of response inhibition in ADHD, however, pertains only to the ADHD-H/I and ADHD-C subtypes (Barkley, 1997). In contrast, most of the ADHD cases in this meta-analysis were either ADHD-IA or ADHD-C, which may explain why we do not see evidence of a stronger relationship. Deficits in inhibition and vigilance have been shown to have both direct and cascaded effects on other executivecontrol strategies in children with ADHD, including working memory, set-shifting and taskswitching, and interference control.

Working Memory-The term working memory (WM) is used to describe a cognitive system in which a limited amount of information can be temporarily stored and manipulated to achieve a mental activity (Andrade, 2001). The importance of this skill for learning and memory has led to several distinct conceptualizations and models. Within the literature on ADHD it has been common to differentiate between measures of verbal and nonverbal WM. Verbal WM is frequently assessed via the digit span task, in which participants are required to listen to, and then repeat back, a series of numbers. The task becomes more difficult as the series of numbers increases in length, if the digits have to be repeated in reverse, or the time between listening and repetition is delayed. In comparison, a Nonverbal WM task asks the participant to recall the location of a series of objects placed in front of them, for example, as in a self-ordered pointing task.

There have been extensive studies of both verbal and nonverbal WM in ADHD, and two rather recent meta-analyses (Martinussen, Hayden, Hogg-Johnson, \& Tannock, 2005; E. G. Willcutt et al., 2005). Following Baddeley's (1986) model of WM, Martinussen et al. (2005) subdivided their meta-analysis into WM tasks that require the storage of information, and those that require storage and manipulation (i.e. are under the control of the central executive (CE)). They reviewed 16 studies on verbal WM storage and 12 on verbal CE. As 
shown in Table 4, the average effect size was in the medium range for both. Willcutt et al. (2005) reviewed 11 studies on verbal WM in ADHD. Although they did not differentiate between storage and CE tasks, they found similar effect sizes to the Martinussen et al. study (2005).

Willcutt et al. (2005) found larger effect sizes for measures of nonverbal WM than for measures of verbal WM (see Table 4). $75 \%$ of the studies in the meta-analysis found significant effects for nonverbal WM in ADHD, compared to 55\% of studies on verbal WM (overall significantly different, $p<.05$ ). Martinussen et al. (2005) went on to examine whether LI and reading disorder (RD) were influential factors in WM in ADHD. Quite surprisingly, they found the presence of these disorders did not contribute to verbal WM deficits (either storage or $\mathrm{CE}$ ), but they did contribute to nonverbal ones. Such a finding is counterintuitive. Looking at a sample of children with the ADHD-C subtype, however, Jonsdottir, Bouma, Sergeant and Scherder (2005) reported opposite results. That is, verbal WM deficits in ADHD were associated with comorbid LI, but this comorbidity was not associated with nonverbal WM. As described above, the dominant paradigm for measuring verbal WM in ADHD has been the digit span task. Because numbers are real words, this presents the possibility that verbal mediation, and thus language ability, will influence performance on verbal WM tasks. The findings of Jonsdottir et al. (2005) are consistent with this hypothesis.

To avoid such a confound, researchers in the field of language development have typically employed nonword repetition tasks (NWR), as opposed to digit span tasks, in the study of WM (Dollaghan \& Campbell, 1998; Gathercole, 2006; Gupta \& Tisdale, 2009). In a nonword repetition task (NWR), the participant hears a made-up word modeled after his or her native language and must then repeat it back. These 'words' vary in length and phonotactic probabilities, and the task becomes harder as the words become longer and less 'word-like' and the cognitive processing load increases (Munson, Kurtz, \& Windsor, 2005). In contrast with the many studies examining NWR in children with LI and RD, only two studies have examined NWR abilities in children with ADHD. Redmond, Thompson and Goldstein (2011) found that children with ADHD performed similarly to controls on the NWR task. In comparison, children with LI (either SLI or ADHD plus LI) performed significantly more poorly. Similar results were reported by Hutchinson, Bavin, Efron and Sciberras (2011), although here, children comorbid for LI and ADHD, as well as children in the LI only group, showed poor NWR performance.

Set-shifting and task-switching-Set-shifting is the ability to display flexibility in the face of changing patterns of reinforcement. It is commonly measured by perseverative errors on the Wisconsin Card Sort Test (WCST). In this, the participant is given a number of stimulus cards. The shapes on the cards differ in color, quantity, and design. The person administering the test decides whether the cards are to be matched e.g., by color, design or quantity. The participant is then given a stack of additional cards and asked to match each one to one of the stimulus cards. The participant is not told how to match the cards; however, s/he is told whether a particular match is right or wrong. The matching rules are changed during the course of the test, and performance is based on the time and number of mistakes made by the participant as s/he is learning the new rule.

Top Lang Disord. Author manuscript; available in PMC 2014 December 12. 
Frazier, Demaree and Youngstrom (2004) reported 25 studies of the WCST in ADHD and found only a small effect size, $d=0.35,95 \%$ CI $[.26, .44]$. Although Willcutt et al. (E. G. Willcutt et al., 2005) reported a slightly larger effect, $d=0.46,95 \%$ CI [.37, .55], this is still considered in the small to moderate range. Findings like these have led Barkley (2005) to conclude that, "problems with cognitive flexibility and set shifting... do not appear to be associated with ADHD, at least with this task".

An alternative to the WCST is the Trail Making-B test. In this, the participant is presented with a page on which numbers and letters are randomly distributed. S/he must then draw a line alternately connecting the numbers and letters in ascending order. In their review, Frazier et al. (2004) reported an average effect size of $d=0.59,95 \%$ CI $[.46, .72]$ in the Trail Making-B test, and Willcutt et al. (2005) reported similar values. Gordon, Barkley and Lovett (2006) concluded the Trail Making-B test was not useful in diagnosing ADHD.

Interference Control-Interference control is most often measured using the Stroop Task. There are three versions of this; the computerized version of the test is simplest to explain so will be used for illustrative purposes. In this version, the participant sees a series of color words (for example, "blue") presented on the computer screen in colors that are incongruent with the word (for example "blue" appears in red font). The participant must name the color of the font, rather than say the color word. To do this, the automatic response of word reading has to be suppressed and prevented from interfering with naming.

Four meta-analyses have reviewed evidence on the Stroop Task in ADHD. Findings ranged from small effects (Hervey, Epstein, \& Curry, 2004; R. Van Mourik, Oosterlaan, \& Sergeant., 2005) to medium (Frazier et al., 2004) to large (Homack \& Riccio, 2003). Lansbergen et al. (2007) suggested the difference between studies can be explained by differences in study sample - children (Homack \& Riccio, 2003; van Mourik, Oosterlaan, \& Sergeant, 2005) versus adults (Hervey et al., 2004); whether or not a computerized version of the test was used; as well as how test scores were calculated.

Summary of executive function-There is good evidence for impairment across a variety of EF measures in ADHD. Response inhibition, vigilance, and working memory are most noteworthy. However, small effect sizes and mixed findings between studies have led researchers to conclude that EF deficits are neither necessary nor sufficient to explain the etiology of the disorder.

\section{State Regulation}

Nigg (2005) has defined state regulation as arousal, activation, and reward motivation. Arousal encompasses alerting, which is a person's ability to respond to changes in sensory stimuli. This is most relevant in the early stages of information processing. Perhaps the best support for an arousal deficit in ADHD comes from the findings of deficits on the continuous performance test. In his meta-analysis, Nigg (2005) reported an average Cohen's $d$ of 0.72 on this task. Barkley (2005) has supported this argument by pointing out that individuals with ADHD show reduced early event related brain responses to novel stimuli, as well as poor EEG evidence in anticipatory activity. 
Activation is response preparation; it can be considered like arousal but without the stimulus-driven features. Concepts of activation are heavily influenced by Sergeant's cognitive-energetic model (2000) in which he argued that activation is associated with response output, duration on task, and "event rate". Event rate effects occur when performance on a task varies as a function of the speed with which the task is presented. Thus, activation is related to the cognitive functions of response inhibition and sustained attention.

The last aspect of State Regulation is reward motivation. This is the ability to use reward signals and to defer actions for future rewards. Multiple studies have identified the existence of atypical response to reinforcements in children with ADHD. One of these observations is the tendency for children with ADHD to choose smaller but immediate rewards over larger delayed ones. Consistent with this finding is research coming out of the field of temporal difference learning (TD learning) showing that a certain type of learning, known as reinforcement learning, is tied to the basal ganglia and dopaminergic systems. More precisely, striatal dopaminergic systems seem to play a role in calculating the probability of future reward (or punishment) that will be derived from an agent's actions in his or her environment (e.g., Dayan \& Niv, 2008; Frank, Moustafa, Haughey, Curran, \& Hutchison, 2007a; Pizzagalli et al., 2008). It has been suggested that altered levels of dopamine receptors and neurotransmitters in individuals with ADHD lead to inefficient/ineffective learning systems in individuals with the disorder (see sections on neuroanatomy and genetics, below, for more detail).

\section{Temporal Processing}

Hypotheses concerning temporal processing disorders have had a prominent place in the literature on SLI (Tallal, 1976). They have only recently, however, been raised with regard to ADHD. This is partly because of brain-imaging studies, which suggest ADHD is associated with abnormal levels of cerebellar activity. Measures of temporal processing employed in the study of ADHD span a wider array of tasks than those used in SLI and include: time perception, estimation and motor timing, time production, and time reproduction (Barkley, 2005). Of these, deficits in time reproduction have been the best supported in studies of ADHD. In a time reproduction task, the participant is presented with a stimulus of a given duration. S/he is then asked to wait for a period of time, after which $\mathrm{s} / \mathrm{he}$ has to reproduce the duration of the stimulus. As Barkley (2005) notes, performance on this task is quite possibly linked to EFs in the form of WM.

\section{Summary}

As we began this section, we noted that research on ADHD has been motivated by the search for a coherent cognitive account of ADHD. There are several well-established deficits in motivation and EFs that have been noted in ADHD, which provide good explanatory appeal for the disorder. However, small effect sizes and mixed findings between studies lead us to conclude that no single unitary construct can explain the disorder. One possible explanation is that unique cognitive profiles do exist, but they pertain only to certain subtypes. Most of the research on the neuropsychology of ADHD has been carried out in groups with the ADHD-C subtype (Nigg, 2005); and it is widely acknowledged that

Top Lang Disord. Author manuscript; available in PMC 2014 December 12. 
investigation into the heterogeneity of subtypes is an area requiring further investigation (Chhabildas et al., 2001). Results of a recent meta-analysis on ADHD subtypes by Willcutt et al., (in press) suggest that inattention symptoms are more strongly associated with weaknesses in a range of neuropsychological domains, including general cognitive ability, short-term and working memory, processing speed, and vigilance. If neuropsychological impairments in ADHD are heterogeneous, this also presents the possibility of causal heterogeneity. This possibility has led several authors to suggest multiple deficit models for ADHD (Castellanos, Sonuga-Barke, Milham, \& Tannock, 2006; B. F. Pennington, 2006; Sonuga-Barke, 2005). One such example is a dual pathway model in which EF and response inhibition deficits serve in one pathway and motivational deficits serve in the other (Castellanos et al., 2006; Sonuga-Barke, 2005).

\section{BRAIN SYSTEMS AND ADHD}

Following the model presented by Tomblin and Mueller (2012), it is expected that the cognitive endophenotypes, which have been outlined above, will be associated with brain systems that support these functions. Indeed, a very nice picture is beginning to emerge for ADHD in this regard. Imaging studies have delineated gross anatomical changes in brain dimensions associated with ADHD (for a review see Bush, Valera, \& Seidman, 2005). The most consistent findings are in an overall reduction in total brain size and reduced dimensions of the caudate nucleus, the prefrontal cortex, the corpus callosum, and the cerebellar vermis within groups of participants with ADHD.

\section{Linking Levels of Endophenotypes and Comorbidity: Brain and Cognition}

Brain imaging studies support the notion that certain brain systems, particularly those involving the basal ganglia and prefrontal cortical regions, are implicated in ADHD. Until very recently, however, there has been little consideration given to the possible roles of the corticostriatal system found within these structures for disorders involving cognition. Indeed, to a great extent, there has been a tacit assumption that cognition is grounded in cortical function.

During the past 20 years, considerable advances have been made with respect to mechanistic models of the corticostriatal system. Current models of the corticostriatal system allow for multiple functions to be served by this system (Pennartz et al., 2009; Seger, 2006). Although traditionally associated with motor function, particularly the selection of motor plans, it is becoming increasingly clear that the corticostriatal system also serves many aspects of habit or procedural learning, as well as categorical learning. A series of authors have expressed the idea that speech production, and spoken and written language, are influenced by this system (Gupta \& McWhinney, 1999; Nicolson \& Fawcett, 2007; Ullman \& Pierpoint, 2005). Thus, the corticostriatal system may be conceived as an endophenotype common to the pathway shared by ADHD with speech, language, and reading disorders.

Within the corticostriatal system, the basal ganglia can be conceived as an interface between the cortical and sub-cortical areas of the brain. As has already been discussed, it has been well documented that impairments in ADHD likely stem from the dysfunction of dopaminergic pathways in the pre-frontal cortical areas of the brain. Cell bundles in the

Top Lang Disord. Author manuscript; available in PMC 2014 December 12. 
basal ganglia produce the neurotransmitter, which acts in the selection (or 'gating') of representations processed by the cortex via (direct) excitatory ("Go") and (indirect) inhibitory ("No Go") pathways. Both biological and computational models have shown that dopaminergic projections to the striatum convey a reward signal that influences several aspects of learning, including working memory, planning, state regulation, and procedural and reinforcement learning (RL) (for example see: Cohen, 2008; Frank, Moustafa, Haughey, Curran, \& E., 2007; Frank, Santamaria, O'Reilly, \& Willcutt, 2007; O'Reilly, 2006). Damage to the basal ganglia, in particular to the striatum, results in impaired reinforcement learning (Frank, Seeberger, \& O'Reilly R, 2004). It has been suggested that altered levels of dopamine receptors and neurotransmitters in children with ADHD possibly leads to inefficient/ineffective learning systems (e.g. Frank et al., 2007a, 2007b).

To test the biological plausibility of this hypothesis for explaining ADHD, Frank et al. (2004) designed a probability selection task in which individuals had to learn the association between pairs of novel stimuli. Feedback was either positive or negative, but was always probabilistic. Adults with ADHD who are off medication were less able to use reinforcement in this paradigm, regardless of whether feedback was positive or negative (Frank, 2007b). When they were on medication, however, they learned from positive reinforcement as well normal controls. Furthermore, Frank et al (2007a) were able to show computationally that genetic variations could predict the extent to which participants learned from positive, versus negative reinforcement. This leads us to consider how genes and genetics affect ADHD.

\section{GENETICS OF ADHD}

ADHD is best viewed as a complex multifactorial disorder. It is influenced by both genetic and environmental components, which are summarized later.

\section{Behavioral genetic studies of ADHD}

Family Studies-Attention-deficit/hyperactivity disorder is both familial and heritable. Several studies have reported elevated rates of ADHD among the biological relatives of children with ADHD, suggesting that familial factors increase susceptibility to the disorder (for a review see: Faraone \& Doyle, 2001). Specifically, 30-35\% of first degree relatives (siblings or parents) of children with ADHD also have the disorder, which is a relative risk 6-8 times higher that of the general population (for a review see: Faraone \& Biederman, 2000).

In the absence of molecular genetic data, family studies cannot disentangle shared genetic from shared environmental factors. For this we can turn to adoption or twin studies. If genes contribute significantly to the risk for ADHD, the disorder should occur more frequently among the biological parents of children with ADHD than among adoptive parents. Two studies of hyperactive children have found this to be the case (Cantwell, 1975; Morrison \& Stewart, 1973). Conversely, it has also been shown that adoptive parents of children with ADHD carry a lower risk than the biological relatives of non-adopted children with ADHD (Sprich, Biederman, Crawford, Mundy, \& Faraone, 2000). 
Twin Studies-Adoption studies are limited by the availability of data, particularly in societies in which adoption records are closed. A complementary method of examining heritability is to study twins. The most straightforward test for genetic influences compares the rate of concordance in monozygotic (MZ) twins, which share nearly $100 \%$ of their genes, to dizygotic (DZ) twins, which share approximately 50\%. If genes influence a disorder, the proportion of twins that are concordant for the disorder will be higher in MZ twins than in DZ twins. More than 20 twin studies of ADHD have been published reporting estimates of heritability between $60 \%$ and nearly $100 \%$. Table 5 shows concordance rates for a subset of eight of these.

The mean heritability across studies has been estimated as $76 \%$ (Faraone et al., 2005). This, and the fact that concordance rates are less than $100 \%$ among MZ twins, suggests environmental factors also play a role in the etiology of ADHD. To tease apart the contribution of shared versus non-shared environmental influences to ADHD, Derks et al. (2004) analyzed data from 9689 3-year-old twin pairs on the CBCL. They found evidence for high genetic contributions to all CBCL syndromes (e.g., oppositional, withdrawn, etc.,). In contrast to the other disorders, however, variation in overactive behavior was influenced by genetic and non-shared environmental factors only (i.e. shared environmental factors did not contribute to the disorder). This finding is important because it had previously been difficult to determine whether the absence of shared environmental influences reported in studies of ADHD was due to the actual absence of these influences, or due to inadequate power to detect them given the size of the twin sample (Rutter et al., 1999).

\section{Molecular genetic studies of ADHD}

Given the high heritability of ADHD, identifying individual genes in the etiology of the disorder has proven surprisingly difficult. It is becoming increasingly clear that single deficit models "one gene, one disorder" are unlikely to provide satisfactory explanation for complex traits and disorders. Research in the pat decade indicates that complex neurobiological disorders, such as ADHD, are likely composed of a much larger number of susceptibility genes acting in concert, each of which contributes only a small magnitude to the overall risk for that trait (Lander \& Schork, 1994). This likely complex multifactorial architecture presents several challenges when it comes to identifying putative risk and goes some way to explain why we do not currently know more about the etiology of the neuropsychological dysfunction in this disorder.

Working from the basis that neurotransmitters play a key role in the psychopathology of disorder, the most targeted gene studies in ADHD have focused on candidates in the dopaminergic, and associated serotonin and norepinephrine systems. Of the genes that have been identified, however, it seems that none are necessary or sufficient to cause the disorder. Rather, the inconsistency in findings across studies points to the likelihood of genetic heterogeneity in the disorder (genetic heterogeneity in the sense that there may be multiple subphenotypes, or endophenotypes, with limited or no overlap at the level of common risk alleles). Moreover, gene-gene and gene-environment interactions likely modulate neural processing mechanism, making the story of how genes influence behavior in this disorder even more complex.

Top Lang Disord. Author manuscript; available in PMC 2014 December 12. 


\section{DISCUSSION}

This overview of the diagnosis and nature of ADHD demonstrates the extent and depth of research on ADHD. As we have shown, there has been considerable effort to examine the diagnostic features of ADHD and, as such, this can be viewed as one of the more validated forms of neurodevelopmental disorders. We have also shown that ADHD serves as an excellent example of how scientific inquiry can link across cognitive, neurological, and genetic levels when considering the underpinnings of a developmental disorder. The following papers (Mueller and Tombin 2012, Lewis et al., 2012; Boada et al., 2012) show that ADHD commonly co-occurs with other developmental disorders in the field of communication disorders. This happens so frequently it has led to a general acceptance of the overlap between these disorders in our field. In the health sciences, however, disease overlap has been explored for the insight it can give into the etiology of disease states. If comorbidity arises from a shared etiology, it should be possible to exploit the extensive research base in ADHD to inform thinking about these disorders and developmental disorders more generally. By the same token, research into ADHD would profit from work on communication disorders. Given this paradigm, researchers in each area need to be well informed about advances in each domain.

\section{Acknowledgments}

This research was supported by grants DC00496 and DC02746 the National Institutes of Health, National Institute on Deafness and Other Communication Disorders

\section{References}

Achenbach, TM.; Rescorla, L. Manual for the ASEBA Achool-Age Forms and Profiles. Burlington, VT: University of Vermot, Research Center for Children, Youth, \& Families; 2001.

Alloway T, Elliott J, Holmes J. The prevalence of ADHD-like symptoms in a community sample. Journal of Attention Disorders. 2010; 14(1):52-56. [PubMed: 20378922]

American Psychiatric, A. Diagnostic and statistical manual of mental disorders (Revised 4th ed). 4. Washington, DC: Author; 2000.

Andrade, J. An introduction to working memory. In: Andrade, J., editor. Working memory in perspective. New York, NY: Taylor \& Francis, Inc; 2001. (Reprinted from: NOT IN FILE)

Applegate B, Lahey BB, Hart EL, Biederman J, Hynd GW, Barkley RA, Shaffer D. Validity of the age-of-onset criterion for ADHD: a report from the DSM-IV field trials. J Am Acad Child Adolesc Psychiatry. 1997; 36(9):1211-1221. [PubMed: 9291722]

Baddeley, AD. Working Memory. Oxford: Oxford University Press; 1986.

Barkley RA. Behavioral inhibition, sustained attention, and executive function: Constructing a unified theory of ADHD. Psychological Bulletin. 1997; 121:65-94. [PubMed: 9000892]

Barkley, RA. Attention-deficit hyperactivity disorder: A handbook for diagnosis and treatment. 3. New York: Guilford Press; 2005.

Barkley RA, Biederman J. Toward a broader definition of the age-of onset criterion for attentiondeficit hyperactivity disorder. J Am Acad Child Adolesc Psychiatry. 1997; 36:1204-1210. [PubMed: 9291721]

Barkley RA, Fischer M, Smallish L, Fletcher K. The persistence of attention-deficit/hyperactivity disorder into young adulthood as a function of reporting source and defintion of disorder. Journal Abnormal Psychology. 2002; 111:279-289.

Barkley RA, Grodzinsky G, DuPaul GJ. Frontal-lobe functions in attention-deficit disorder with and without hyperactivity. Journal Abnormal Child Psychology. 1992; 20:163-188.

Top Lang Disord. Author manuscript; available in PMC 2014 December 12. 
Barkley, RA.; Murphy, K.; Fischer, M. ADHD in Adults: What the Science Says. New York: Guilford; 2010.

Biederman J, Faraone SV. The Massachusetts General Hospital studies of gender influences on attention-deficit/hyperactivity disorder in youth and relatives. Psychiatry Clinc North America. 2004; 27:225-232.

Biederman J, Faraone SV. Attention-deficit hyperactity disorder. The Lancet. 2005; 366:237-248.

Bush G, Valera EM, Seidman LJ. Functional neuroimaging of attention-deficit/hyperactivity disorder: a review and suggested future directions. Biol Psychiatry. 2005; 57(11):1273-1284.10.1016/ j.biopsych.2005.01.034 [PubMed: 15949999]

Cantwell DP. Genetics of hyperactivity. J Child Psychol Psychiatry. 1975; 16:261-264. [PubMed: 1171894]

Castellanos X, Sonuga-Barke E, Milham MP, Tannock R. Characterizing cognition in ADHD: beyond executive dysfunction. Trends Cogn Sci. 2006; 10(3):117-123. [PubMed: 16460990]

Chhabildas NA, Pennington BF, Willcutt EG. A comparison of the neuropsychological profiles of the DSM-IV subtypes of ADHD. Journal Abnormal Child Psychology. 2001; 29(6):529-520.

Cohen MX. Neurocomputational mechanisms of reinforcement-guided learning in humans: a review. Cogn Affect Behav Neurosci. 2008; 8(2):113-125. [PubMed: 18589502]

Conners, K. The Conners Comprehensive Rating Scales. San Antonio, TX: Pearson; 2008.

Curt, J.; Stabile, M. Child mental health and human capital accumulation: The case of ADHD. 2004. from http://www.nber.org/papers/w10435

Davidson MA. ADHD in Adults. A review of the literature. Journal of Attention Disorders. 2008; 11(6):628-641. [PubMed: 18094324]

Disorder, AAoPCoQISoA-DH. Diagnosis and evaluation of the child with attention deficit/ hyperactivity disorder. Pediatrics. 2000; 105:1158-1170. [PubMed: 10836893]

Dollaghan C, Campbell TF. Nonword repeition and child language impairment. Journal of Speech, Language, and Hearing Research. 1998; 41:1136-1146.

DuPaul, GJ.; Power, TJ.; Anastopoulos, AD.; Reid, R. ADHD Rating Scale-IV: Checklist, norms, and clinical interpreation. New York, NY: The Guillford Press; 1998.

Faraone SV, Biederman J. Nature, nurture, and attention deficit hyperactivity disorder. Dev Rev. 2000; 20:568-581.

Faraone SV, Biederman J, Mick E. The age-dependent decline of attention deficit hyperactivity disorder: a meta-analysis of follow-up studies. Psychol Med. 2006; 36(2):159-165.10.1017/ S003329170500471X [PubMed: 16420712]

Faraone SV, Biederman J, Monuteaux MC. Further evidence for the diagnostic continuity between child and adolescent ADHD. Journal of Attention Disorders. 2002; 6(5):5-13. [PubMed: 12045756]

Faraone SV, Perlis RH, Doyle AE, WSJ, Goralnick JJ, Holmgren MA, Sklar P. Molecular genetics of Attention-Deficit/Hyperactivity Disorder. Biol Psychiatry. 2005; 57:1313-1323. [PubMed: 15950004]

Faraone SV, Sergeant J, Gillberg C, Biederman J. The worldwide prevalence of ADHD: Is it an American condition? World Psychiatry. 2003; 2:104-113. [PubMed: 16946911]

Farone, SV.; Biederman, J.; Kiely, K. Cognitive functioning, learning disability, and school failure in attention hyperactivity disorder: a family study perspective. In: Beitchman, JH.; Cohen, NJ.;

Konstanteras, MM.; Tannock, R., editors. Language, learning, and behavior disorders. Cambridge: Cambridge University Press; 1996. p. 247-269.

Farone SV, Biederman J, Spencer T, Wilens T, Seidman LJ, Mick E. Attention-deficit hyperactivity disorder in adults: An overview. Biological Psychology. 2000; 48:9-20.

Frank MJ, Moustafa AA, Haughey HM, Curran T, EHK. Genetic triple dissociation reveals multiple roles for dopamine in reinforcement learning. PNAS. 2007; 104(41):16311-16316. [PubMed: 17913879]

Frank MJ, Santamaria A, O'Reilly RC, Willcutt EG. Testing computational models of dopamine and noradrenaline dysfunction in Attention Deficit/Hyperactivity Disorder.

Neuropsychopharmacology. 2007; 32:1583-1599. [PubMed: 17164816]

Top Lang Disord. Author manuscript; available in PMC 2014 December 12. 
Frank MJ, Seeberger LC, O'Reilly RC. By carrot or by stick: cognitive reinforcement learning in parkinsonism. Science. 2004; 306(5703):1940-1943.10.1126/science.1102941 [PubMed: 15528409]

Frazier TW, Demaree HA, Youngstrom EA. Meta-analysis of intellectual and neuropsychological test performance in attention-deficit/hyperactivity disorder. Neuropsychology. 2004; 18(3):543-555. [PubMed: 15291732]

Frick PJ, Nigg J. Current Issues in the Diagnosis of Attention Deficit Hyperactivity Disorder, Oppositional Defiant Disorder, and Conduct Disorder. Annual Review of Clinical Psychology. 2012:8.

Gathercole SE. Complexities and constraints in nonword repetition and word learning. Applied Psycholinguistics. 2006; 27(4):599-613.

Gaub M, Carlson CL. Behavioral characteristics of DSM-IV ADHD subtypes in a school-based populations. Journal Abnormal Child Psychology. 1997; 25(2):103-111.

Gershon J. A meta-analytic revuew of gender differences in ADHD. Journal of Attention Disorders. 2002; 5:143-154. [PubMed: 11911007]

Gupta, P.; McWhinney, B. The emergence of language from serial order and procedural memory. In: McWhinney, B., editor. The Emergence of Language. Mahwah, NJ: Lawrence Erlbaum; 1999. p. 447-482.

Gupta P, Tisdale J. Does Phonological Short-term memory causally determine vocabulary learning? Twoard a computational resolution of the debate. Journal of Memory and Language. 2009

Harpin VA. The effet of ADHD on the life of an individual, their family, and community from preschool to adult life. Arch Dis Child. 2005; 90(Supple I):i2-17. [PubMed: 15665153]

Heiligenstein E, Keeling RP. Presentation of unrecognized attention deficit hyperactivity disorder in college students. Journal of American College Health. 1995; 43:226-229. [PubMed: 7499637]

Hervey AS, Epstein JN, Curry JF. Neuropsychology of adults with attention-deficit/hyperactivity disorder: a meta-analytic review. Neuropsychology. 2004; 18(3):485503.10.1037/0894-4105.18.3.485 [PubMed: 15291727]

Homack S, Riccio CA. A meta-analysis of the sensitivity and specificity of the Stoop Color and Word Test with children. Archives of Clinical Neuropsychology. 2003; 19:725-743. [PubMed: 15288327]

Karmiloff-Smith A. Development itself is the key to understanding developmental disorders. Trends in Cognitive Science. 1998; 2:389-398.

Kessler RC, Adler L, Barkley AM, Birnbaum H, Johnston JA, Spencer T, Ustun TB. The prevalnce and effects of adult attention/hyperactivity disorder on work performance in a nationally representative sampels of workers. Journal of Occupational and Environmental Medicine. 2005; 47:565-572. [PubMed: 15951716]

Konrad K, Neufang S, Hanisch C, Fink GR, Herpertz-Dahlmann B. Dysfunctional attentional networks in children with attention deficit/hyperactivity disorder: Evidence from an event-related functional magnetic resonance imagin study. Biol Psychol. 2005; 59:643-651.

Lahey BB, Applegate B, McBurnett K, Biederman J, Greenhill L, Hynd GW, Shaffer D. DSM-IV field trials for attention deficit and hyperactivity disorder in children and adolescents. American Journal of Psychiatry. 1994; 151:1673-1685. [PubMed: 7943460]

Lahey BB, Pelham WE, Loney J, Lee SS, Willcutt EG. Instability of the DSM-IV subtypes of ADHD from preschool through elementary school. Archives of General Psychiatry. 2005; 62:896-902. [PubMed: 16061767]

Lansbergen MM, Kenemans JL, van Engeland H. Stroop interference and attention-deficit/ hyperactivity disorder: A review and meta-analysis. Neuropsychology. 2007; 21(2):251262.10.1037/0894-4105.21.2.251 [PubMed: 17402825]

Li J, Zhang X, Wang Y, Zhou R, Zhang H, Yang L, Faraone SV. The serotonin 5-HT1D receptor gene and attention-deficit hyperactivity disorder in Chinese Han subjects. Am J Med Genet B Neuropsychiatr Genet. 2006; 141B(8):874-876.10.1002/ajmg.b.30364 [PubMed: 17099886]

Martinussen R, Hayden J, Hogg-Johnson S, Tannock R. A meta-analysis of working memory impairments in children with attention-deficit/hyperactivity disorder. J Am Acad Child Adolesc Psychiatry. 2005; 44(4):377-384. [PubMed: 15782085] 
McBurnett K, Pfiffner LJ, Wiilcutt E, Tamm L, Lerner M, Ottolini YL, Furman MB. Experimental cross-validation of DSM-IV types of attention-deficit/hyperactivity disorder. J Am Acad Child Adolesc Psychiatry. 1999; 38(1):17-24. [PubMed: 9893412]

McGough JJ, Barkley RA. Diagnostic controversies in adult Attention Deifict Hyperactivity Disorder. The American Journal of Psychiatry. 2004; 161:1948-1965. [PubMed: 15514392]

Milich R, Balentine AC, Lynam D. ADHD Combined Type and ADHD Predominantly Inattentive Type are distinct and unrelated disorders. Clinical Psychology: Science and Practice. 2001; 8(4): 463-488.

Morrison JR, Stewart MA. The psychiatric status of the legal families of adopted hyperactive children. Arch Gen Psychiatry. 1973; 28:888-891. [PubMed: 4707995]

Munson B, Kurtz BA, Windsor J. The influence of vocabulary size, phonotactic probability, and wordlikeness on nonword repetitions of children with and without Specific Language Impairment. Journal of Speech, Language, and Hearing Research. 2005; 48:1033-1047.

Murphy K, Barkley RA. Prevalence of DSM-IV symptoms of ADHD in adult licensed drivers: Implications for clinical diagnosis. Journal of Attention Disorders. 1996; 1:147-161.

Nicolson RI, Fawcett AJ. Procedural learning difficulties: reuniting the developmental disorders? Trends Neurosci. 2007; 30(4):135-141.10.1016/j.tins.2007.02.003 [PubMed: 17328970]

Nigg JT. Neuropsychologic Theory and Findings in Attention-Deficit/Hyperactivity Disorder: The State of the Field and Salient Challenges for the Coming Decade. Biol Psychiatry. 2005; 57(11): 1424-1435.10.1016/j.biopsych.2004.11.011 [PubMed: 15950017]

O'Reilly RC. Biologically based computational models of high-level cognition. Science. 2006; 314(5796):91-94.10.1126/science.1127242 [PubMed: 17023651]

Oosterlaan J, Logan GD, Sergeant JA. Response Inhibition in AD/HD, CD, Comorbid AD/HD+CD, Anxious, and Control Children: A Meta-analysis of Studies with the Stop Task. Journal of Child Psychology and Psychiatry. 1998; 39(3):411-425.10.1111/1469-7610.00336 [PubMed: 9670096]

Pastor PN, Reuben CA. Diagnosed attention deficit hyperactivity disorder and learning disability: United States, 2006-2006. National Center for Health Statistics. Vital and Health Statistics. 2008; $10(237)$

Pennartz CM, Berke JD, Graybiel AM, Ito R, Lansink CS, van der Meer M, Voorn P. Corticostriatal Interactions during Learning, Memory Processing, and Decision Making. J Neurosci. 2009; 29(41):12831-12838.10.1523/JNEUROSCI.3177-09.2009 [PubMed: 19828796]

Pennington BF. From single to multiple deficit modesl of developmental disorders. Cognition. 2006; 101:385-413. [PubMed: 16844106]

Pennington BF, Ozonoff S. Executive funtion and developmental pyschopathology. Journal of Child Psycholgy and Psychiatry. 1996; 37:51-87.

Ramsay JR, Rostain AL. Issues in ADHD in adults. The ADHD Report. 2006; 14(6):5-8.

Scahill L, Schwab-Stone M. Epidemiology of ADHD in school-age children. Child and Adolesent Psychiatric Clinics of North America. 2009; 27:225-232.

Schachar R, Tannock R, Cunningham CC, Corkum PV. Behavioral, situational, and temporal effects of ADHD with methylphenidate. Journal of the American Academy of Child and Adolescent Psychiatry. 1997; 36:754-763. [PubMed: 9183129]

Seger CA. The basal ganglia in human learning. Neuroscientist. 2006; 12(4):285290.10.1177/1073858405285632 [PubMed: 16840704]

Sergeant J. The cognitive-energetic model: an empirical approach to Attention-Deficit Hyperactivity Disorder. Neuroscience and Biobehavioral Reviews. 2000; 24(1):7-12. [PubMed: 10654654]

Sonuga-Barke E. Causal models of Attention-Deficit/Hyperactivity Disorder: From ommon simple deficits to multiple developmental pathways. Biological Psychiatry. 2005; 57(11):1231-1238. [PubMed: 15949993]

Sprich S, Biederman J, Crawford MH, Mundy E, Faraone SV. Adoptive and biological families of children and adolescents with ADHD. J Am Acad Child Adolesc Psychiatry. 2000; 39:1432-1437. [PubMed: 11068899]

Steinkamp MW. Relationships between environmental distractions and task performance of hyperactive and normal children. J Learn Disabil. 1980; 13(4):209-214. [PubMed: 7381317]

Top Lang Disord. Author manuscript; available in PMC 2014 December 12. 
Szatmari P, Offord DR, Boyle MH. Correlates, associated impairments and pattern of service utilization of children with attention deficit disorder: Findings from the Ontario Health Study. Journal of Child Psycholgy and Psychiatry. 1989; 30:205-217.

Ullman M, Pierpoint EI. Specific language impairment is not specific to language: The procedural deficit hypothesis. Cortex. 2005; 41:399-433. [PubMed: 15871604]

van Mourik R, Oosterlaan J, Heslenfeld DJ, Konig CE, Sergeant JA. When distraction is not distracting: A behavioral and ERP study on distraction in ADHD. Clinical Neurophysiology. 2007; 118(8):1855-1865.10.1016/j.clinph.2007.05.007 [PubMed: 17576093]

Van Mourik R, Oosterlaan J, Sergeant J. The Stroop revisited: a meta-analysis of interference control in ADHD. The Jorunal of Child Psycholgy and Psychiatry. 2005; 46:150-165.

Willcutt E, Pennington BF. Comorbidity of reading disability and Attention-Deficit/Hyperactivity Disoder: Differences by gender and subtype. J Learn Disabil. 2000; 33(2):179-191. [PubMed: 15505947]

Willcutt EG, Doyle AE, Nigg JT, Faraone SV, Pennington BF. Validity of the executive funtion theory of Attention Deficit/Hyperactivity Disorder: A meta-analytic review. Biol Psychiatry. 2005; 57:1336-1346. [PubMed: 15950006]

Willcutt EG, Hartung CM, Lahey BB, Loney J, Pelham WE. Utility of behavior ratings by examiners during assessments of preschool children with attention-deficit/hyperactivity disorder. Journal of Abnormal Child Psychology. 1999; 27(6):463-472. [PubMed: 10821628] 


\section{Table 1}

DSM-IV-TR Criteria for ADHD Diagnosis (APA, 2000)

\section{Inattention}

Often fails to give close attention to details or makes careless mistakes in schoolwork, work, or other activities

Often has difficulty sustaining attention in tasks or play activities

Often does not seem to listen when spoken to directly

Often does not follow through on instructions and fails to finish schoolwork, chores, or duties in the workplace

Often has difficulty organizing tasks and activities

Often avoids, dislikes, or is reluctant to engage in tasks that require sustained mental effort

Often loses things necessary for tasks or activities

Is often easily distracted by extraneous stimuli

Is often forgetful in daily activities

\section{Hyperactivity}

Often fidgets with hands or feet or squirms in seat.

Often leaves seat in classroom or in other situations in which remaining seated is expected.

Often runs about or climbs excessively in situations in which it is inappropriate.

Often has difficulty playing or engaging in leisure activities quietly

Is often "on the go" or often acts as if "driven by a motor"

\section{Impulsivity}

Often talks excessively

Often blurts out answers before questions have been completed

Often has difficulty awaiting turn

Often interrupts or intrudes on others (e.g. butts into conversations or games) 


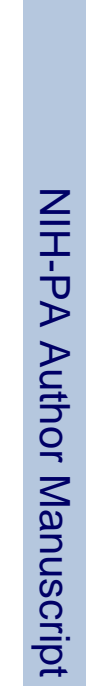

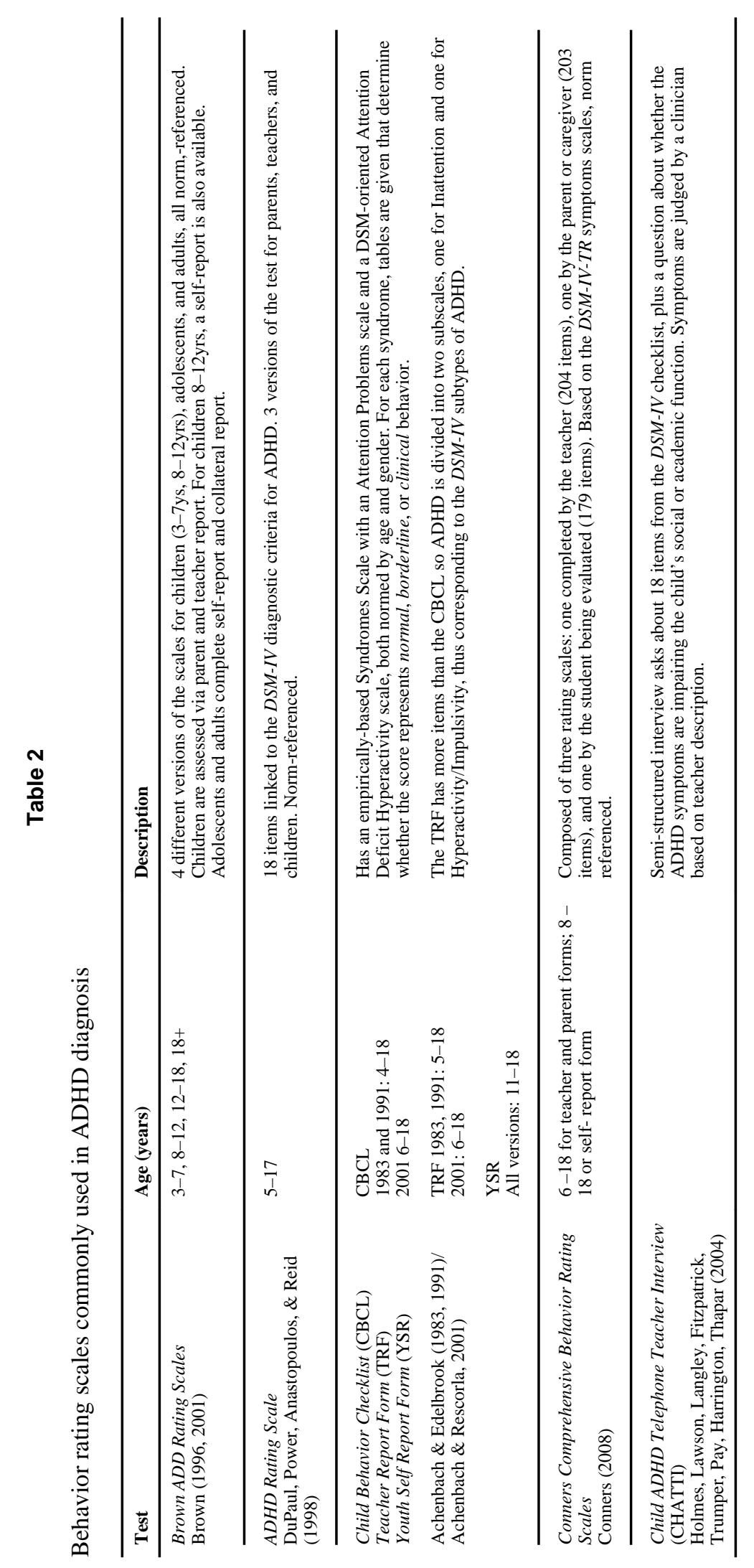

Top Lang Disord. Author manuscript; available in PMC 2014 December 12. 


\section{Table 3}

\section{Cognitive Functions in ADHD}

\begin{tabular}{|c|c|c|}
\hline Task name & Description & \\
\hline Stop-signal reaction time & The time taken to inhibit an ongoing action & RI \\
\hline $\begin{array}{l}\text { Continuous Performance Test - } \\
\text { commission errors }\end{array}$ & Response to a sequence other than the target sequence & RI \\
\hline $\begin{array}{l}\text { Continuous Test Performance - } \\
\text { omission errors }\end{array}$ & Failure to respond to the target sequence & SA \\
\hline $\begin{array}{l}\text { Wisconsin Card Sorting Task } \\
\text { perseverative errors }\end{array}$ & $\begin{array}{l}\text { Errors that reflect difficulty shifting to a new rule when provided with feedback indicating } \\
\text { that the previous rule is no longer correct }\end{array}$ & SS \\
\hline Trailmaking Test Part B & $\begin{array}{l}\text { Timed task that requires the individual to connect a series of letters and numbers in } \\
\text { ascending order while alternating between numbers and letters }\end{array}$ & SS \\
\hline Tower of Hanoi/London & $\begin{array}{l}\text { The goal is to move one stack of objects from one position to another while adhering to a } \\
\text { set of rules (i.e. a large ring cannot be placed on top of a small ring) }\end{array}$ & $\mathrm{P}$ \\
\hline Porteus Maze & $\begin{array}{l}\text { The individual must plan ahead to reach the only exit of a series of mazes without } \\
\text { backtracking or crossing any lines }\end{array}$ & $\mathrm{P}$ \\
\hline Rey-Osterrith Complex Figure Test & $\begin{array}{l}\text { The subject copies an abstract design, and the response is scored based on its } \\
\text { organizational quality }\end{array}$ & $\mathrm{P}$ \\
\hline Working Memory Sequence Span & $\begin{array}{l}\text { The participant provides the last word for a set of simple sentences read by the examiner } \\
\text { and then is required to produce each word that s/he provided after all sentences are } \\
\text { completed }\end{array}$ & VWM \\
\hline Digits Backward & $\begin{array}{l}\text { The subject repeats a series of digits in the reverse order to that in which they were } \\
\text { presented }\end{array}$ & VWM \\
\hline Self-ordered pointing & $\begin{array}{l}\text { Requires the subject to select a different design on each card in a series without selecting } \\
\text { the same designed twice }\end{array}$ & SWM \\
\hline CANTAB Spatial Working Memory & $\begin{array}{l}\text { The subject searches spatial locations to fin tokens while remembering not to return to any } \\
\text { locations where tokens were previously found }\end{array}$ & SWM \\
\hline Stroop Test & The subject must name the color of color-content mismatching color-words & IC \\
\hline
\end{tabular}

$\mathrm{RI}=$ response inhibition; $\mathrm{SA}=$ sustained attention; $\mathrm{SS}=$ set shifting; $\mathrm{P}=$ planning; $\mathrm{VWM}=$ verbal working memory; $\mathrm{SWM}=$ spatial working memory; IC = interference control 
Table 4

Average effect sizes for components of working memory in two meta-analyses of ADHD

\begin{tabular}{l|l|l|l}
\hline & & \multicolumn{2}{|l}{ Effect size (Cohen's $\boldsymbol{d}$ ) and CI } \\
\hline Meta-analysis & WM Memory System & Verbal & Nonverbal \\
\hline \multirow{2}{*}{ Martinssen et al. (2005) } & Storage & $0.47(0.36-0.59)$ & $0.85(0.62-1.08)$ \\
\cline { 2 - 4 } & Central Executive & $0.43(0.24-0.62)$ & $1.14(0.82-1.46)$ \\
\hline Willcutt et al. (2005) & Working Memory & $0.55(0.44-0.65)$. & $.63(0.47-0.79)$ \\
\hline
\end{tabular}


Table 5

Concordance rates for ADHD in MZ and DZ twins (taken from Willcutt et al., 2010)

\begin{tabular}{lllll}
\hline & \multicolumn{2}{l}{ Number of pairs } & \multicolumn{2}{l}{ Probandwise concordance \% } \\
\cline { 2 - 5 } & \multicolumn{1}{l}{ DZ } & MZ & DZ \\
\cline { 2 - 5 } Goodman \& Stevenson (1989) & 39 & 54 & 51 & 33 \\
Levy et al. (1997) & 57 & 46 & 82 & 38 \\
Levy et al (2001) & 138 & 109 & 67 & 42 \\
Sherman et al (1997) & 69 & 32 & 58 & 31 \\
Thapar et al. (2001) & $175^{*}$ & $410 *$ & 79 & 54 \\
Todd et al. (2001) & 72 & 135 & 68 & 22 \\
Willcutt et al. (2000) & 88 & 82 & 78 & 38 \\
Willcutt et al. (2007) & 83 & 78 & 68 & 24 \\
Weighted average & & & 71 & 41 \\
\hline
\end{tabular}

${ }^{*}$ specific Ns were not provided, so Ns are estimated based on the total sample and the $80^{\text {th }}$ percentile threshold were used to define ADHD probands. 
Table 6

Summary of evidence for familiarity and heritability in ADHD

\begin{tabular}{ll} 
Mean heritability estimate & .76 \\
Relative risk to $1^{\text {st }}$ degree relatives & $6-8$ times higher than the general population \\
MZ concordance & $51-82 \%$ \\
DZ concordance & $22-54 \%$ \\
\hline
\end{tabular}




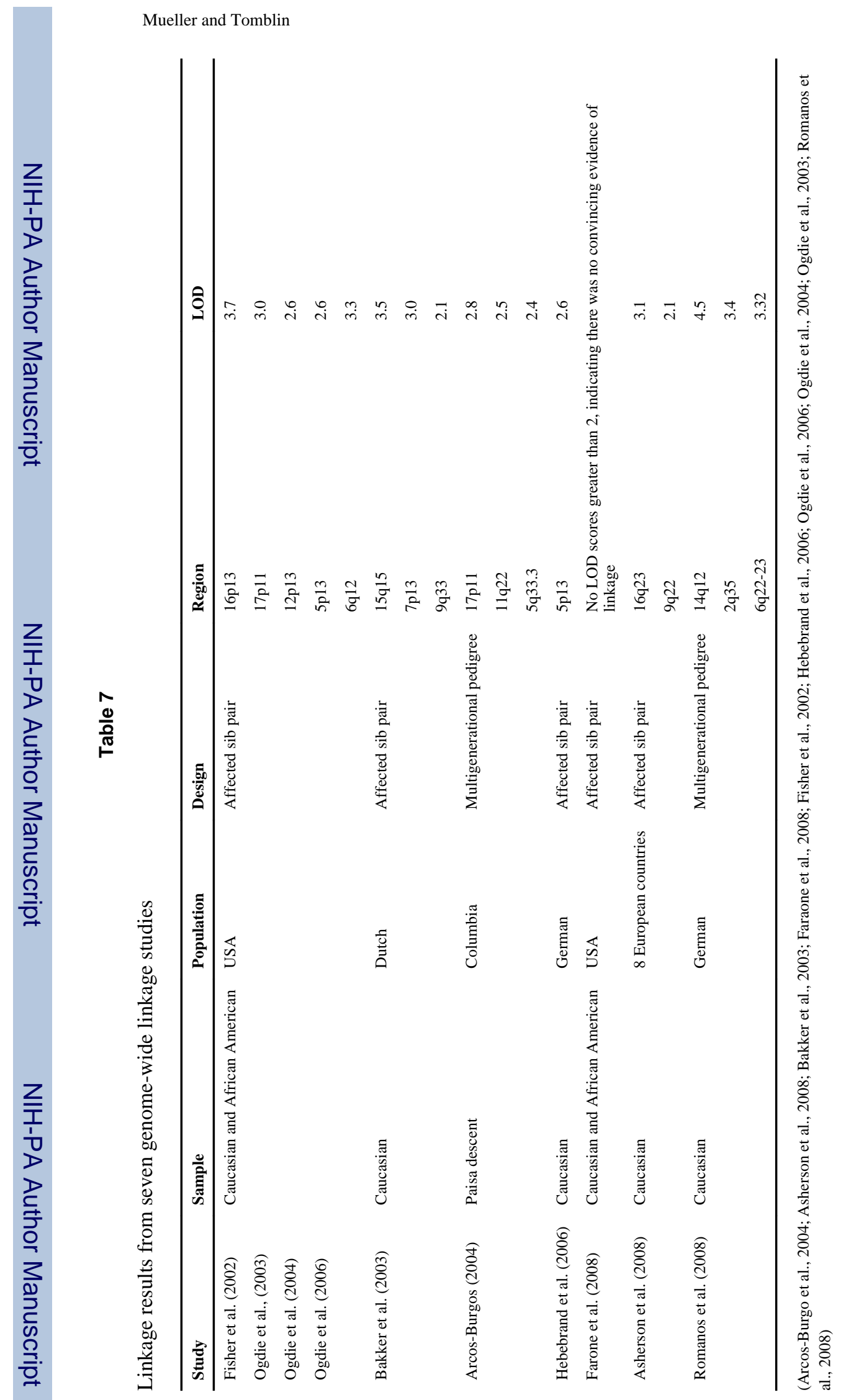

Top Lang Disord. Author manuscript; available in PMC 2014 December 12. 